\title{
Effect of Hypoxia on Lipid Accumulation in Cultured Fibroblasts from Normal Rabbit and Watanabe Heritable Hyperlipidemic Rabbit
}

\author{
Manabu Tsukitani, ${ }^{1}$ Ryozo OKamoto, ${ }^{1}$ Yuichi Ishikawa,,${ }^{1, *}$ \\ Junichi Mukodani, ${ }^{1}$ Naoya Watanabe, ${ }^{1}$ Atsuo Suehiro, ${ }^{1}$ \\ Makoto Hatani, ${ }^{1}$ Motohiro Fujino, ${ }^{1}$ Shinji Takano, ${ }^{1}$ \\ Yoshio Watanabe, ${ }^{2}$ and Hisashi FukUZAKI ${ }^{1}$
}

${ }^{1}$ The First Department of Internal Medicine and ${ }^{2}$ Institute for Experimental Animals, Kobe University School of Medicine, Kobe 650, Japan

(Received December 19, 1986)

\begin{abstract}
Summary We studied the effect of hypoxia on lipid accumulation in cultured fibroblasts from normal rabbits (normal fibroblasts) and in low density lipoprotein (LDL) receptor-negative fibroblasts from WHHL (Watanabe heritable hyperlipidemic) rabbits (WHHL fibroblasts). These cells were incubated in medium with normolipemic rabbit serum (NRS) or hyperlipemic rabbit serum (HRS). The cells were incubated in a humidified atmosphere of either $20 \% \mathrm{O}_{2}, 75 \% \mathrm{~N}_{2}$, and $5 \% \mathrm{CO}_{2}$ (control cells) or $2 \% \mathrm{O}_{2}, 93 \% \mathrm{~N}_{2}$, and $5 \% \mathrm{CO}_{2}$ (hypoxic cells).

After $48 \mathrm{~h}$ incubation of normal fibroblasts in medium with $20 \%$ NRS, free fatty acid (FFA) levels were increased slightly and the triglyceride (TG) level markedly in hypoxic cells. In the medium with $20 \%$ HRS, in addition to the increased FFA and TG levels, the free cholesterol level was increased slightly and the esterified cholesterol level markedly in hypoxic cells. Moreover, in WHHL fibroblasts, which lack LDL receptors, cellular lipid accumulation was also observed after $48 \mathrm{~h}$ incubation in the medium with $20 \% \mathrm{HRS}$, and hypoxic incubation enhanced the cellular cholesterol and TG accumulation, as in normal fibroblasts.

These results suggest that under hyperlipemic conditions, non LDL receptor-mediated uptake of lipoproteins plays a major role in cellular lipid deposition and that tissue hypoxia promotes lipid accumulation in peripheral cells by the LDL receptor-independent mechanisms.
\end{abstract}

Key Words: atherosclerosis, hyperlipemia, hypoxia, LDL receptor, WHHL rabbit

\footnotetext{
*To whom correspondence should be addressed.
} 
Cultured skin fibroblasts possess specific high-affinity receptors that bind low density lipoproteins (LDL) on their cell surfaces. It is believed that the receptormediated uptake of LDL is the major process by which most extrahepatic cells take up cholesterol [1]. But the role of LDL receptors in lipid deposition in cells remains uncertain.

We previously reported that hypoxia $\left(2 \% \mathrm{O}_{2}\right)$ promoted cholesterol accumulation, especially that of the esterified form, in cultured rabbit aortic smooth muscle cells under hyperlipemic conditions. It was thus suggested that hypoxia plays an important role in atherogenesis [2].

The present study was designed to evaluate the role of LDL receptors in peripheral cells under hyperlipemic conditions, and the effect of hypoxia on lipid accumulation (not only of cholesterol but also of other lipids) in peripheral cells, using cultured skin fibroblasts from normal rabbits (normal fibroblasts) and LDL receptor negative fibroblasts from WHHL (Watanabe heritable hyperlipidemic) rabbits (WHHL fibroblasts) [3-6].

\section{MATERIALS AND METHODS}

Serum. Normolipemic rabbit serum (NRS) was obtained from male Japanese White rabbits fed a normal rabbit chow diet, and hyperlipemic rabbit serum (HRS) was obtained from animals fed a rabbit chow diet supplemented with $1 \%$ cholesterol for at least one month. Blood was collected from the rabbits after an overnight fast by puncturing the marginal ear vein without the use of anesthesia. Serum was obtained by centrifugation and sterilized by filtration through $0.45-\mu \mathrm{m}$ filters (Millipore Japan, Tokyo). Serum cholesterol, triglyceride, and phospholipid were measured by enzymatic techniques, using Determiner TC '5 (Kyowa Hakko Kogyo, Tokyo), triglyceride C II-Test (Wako Pure Chemical Industries, Osaka), and PL kit-K (Nippon Shoji, Tokyo), respectively.

Preparation of lipoprotein-deficient serum (LPDS). LPDS $(d>1.21 \mathrm{~g} / \mathrm{ml})$ from NRS was isolated by ultracentrifugation, as described by Havel et al. [7]. The fraction was dialysed against $0.15 \mathrm{M} \mathrm{NaCl}$ containing $0.01 \%$ EDTA, $\mathrm{pH} 7.4$, and sterilized by filtration through $0.45-\mu \mathrm{m}$ filters.

Cells. LDL receptor positive skin fibroblasts were obtained from a normal Japanese White rabbit, and LDL receptor-negative fibroblasts, from a WHHL rabbit [4-6]. Cells were cultured in a humidified $\mathrm{CO}_{2}(5 \%)$ incubator at $37^{\circ} \mathrm{C}$ in 75- $\mathrm{cm}^{2}$ flasks (Corning) containing Eagle's minimum essential medium (Nissui, Tokyo) supplemented with Kanamycin $(100 \mu \mathrm{g} / \mathrm{ml}), 1 \%(\mathrm{v} / \mathrm{v})$ nonessential amino acids (GIBCO), 10\% (v/v) newborn calf serum (GIBCO), $20 \mathrm{~mm}$ Tricine (P-L Biochemicals) and $\mathrm{NaHCO}_{3}$ at $\mathrm{pH}$ 7.4. The medium was changed every third day. Cells in the stationary phase of growth were subcultured at a $3: 1$ split ratio following detachment by washing with Dulbecco's phosphate-buffered saline (PBS) and incubation with $0.05 \%$ trypsin- $0.02 \%$ EDTA solution for $7-10 \mathrm{~min}$ at $37^{\circ} \mathrm{C}$. All cells used in the experiments had been grown in monolayers for 7-9 generations. 
For the experiments, cells were seeded in $60-\mathrm{mm}$ plastic Petri dishes at a density of $4.5 \times 10^{5}$ cells/dish and incubated for 3 days until subconfluent. After the growth medium was removed, the cells were washed once with PBS and incubated with $3 \mathrm{ml}$ of medium containing LPDS $(2.5 \mathrm{mg}$ of protein $/ \mathrm{ml})$ for $24 \mathrm{~h}$ in order to activate LDL receptors. Then the medium was removed and $3 \mathrm{ml}$ of medium containing $20 \%$ NRS or HRS was added to each dish. The cells were transferred either to the incubator conditioned with $20 \% \mathrm{O}_{2}, 75 \% \mathrm{~N}_{2}$, and $5 \%$ $\mathrm{CO}_{2}$ (control cells) or the incubator with $2 \% \mathrm{O}_{2}, 93 \% \mathrm{~N}_{2}$, and $5 \% \mathrm{CO}_{2}$ (hypoxic cells). After a $48 \mathrm{~h}$ incubation, the culture medium was removed, and the cells were rinsed twice with PBS and harvested with $0.05 \%$ trypsin- $0.02 \%$ EDTA solution. Cells from these dishes were collected in a conical centrifuge tube and washed three times with $0.9 \% \mathrm{NaCl}$ solution by repeated centrifugation $(2,000 \mathrm{rpm}$ for 5 min each time).

Cellular lipid analyses. Lipids were extracted from the washed cell pellet using the method of Folch et al. [8]. Namely, $1 \mathrm{ml}$ of methanol was added to each tube containing a washed cell pellet. After sonication of the cell pellet for $1 \mathrm{~min}$ using the microtip of the sonifier (Sonifier B-12 Branson Sonic Power, Danbury Conn. U.S.A.), $2 \mathrm{ml}$ of chloroform were added. After mixing an centrifugation (3,000 rpm for $10 \mathrm{~min})$, the clear supernatant was transferred to a glass tube, and the sediment was washed twice with $1 \mathrm{ml}$ of chloroform-methanol $(2: 1)$ mixture by repeated centrifugation $(3,000 \mathrm{rpm}$ for $10 \mathrm{~min})$. The dry sediment was dissolved in $0.5 \mathrm{~N} \mathrm{NaOH}$ and an aliquot was taken for protein determination by the method of Lowry et al. [9]. One $\mathrm{ml}$ of $0.5 \% \mathrm{NaCl}$ was added to $5 \mathrm{ml}$ of crude lipid extract, and the two liquids were mixed vigorously. After centrifugation $(3,000 \mathrm{rpm}$ for 10 $\mathrm{min}$ ), the lower phase was taken for lipid analysis, and an aliquot was evaporated under reduced pressure. Free and total cholesterol were determined by the enzymatic fluorometric method of Heider and Boyett [10]. The esterified cholesterol content was determined by subtraction of free cholesterol content from that of total cholesterol. Triglyceride (TG) was determined by the method of Fletcher, free fatty acid (FFA) by the modified Itaya-Ui's method, and phospholipid (PL) was measured by Hoeflmayr-Fried's method [11]. All the results were expressed per mg of cell protein, and statistical significance was calculated using the Student's $t$-test.

\section{RESULTS}

After $48 \mathrm{~h}$, the hypoxic cultures exhibited growth inhibition, the cellular protein per dish being approximately $60 \%$ of the control culture value.

Table 1 shows the lipid contents of the control $\left(20 \% \mathrm{O}_{2}\right)$ and the hypoxic $(2 \%$ $\mathrm{O}_{2}$ ) cells after a $48 \mathrm{~h}$ incubation in medium containing $20 \% \mathrm{NRS}$ or $20 \% \mathrm{HRS}$. In the medium containing $20 \%$ NRS, the FFA levels of hypoxic cells were $44 \%$ higher than those of control cells (in both normal fibroblasts and WHHL fibroblasts). In the medium containing $20 \%$ HRS, FFA levels of hypoxic cells from normal and WHHL rabbits were $26 \%$ and $22 \%$ higher, respectively. The TG 
Table 1. Lipid content of cultured normal and WHHL fibroblasts incubated with a medium containing $20 \%$ NRS or HRS under either control or hypoxic conditions for $48 \mathrm{~h}$.

\begin{tabular}{|c|c|c|c|c|}
\hline & \multicolumn{2}{|c|}{ Normal fibroblasts } & \multicolumn{2}{|c|}{ WHHL fibroblasts } \\
\hline & $20 \% \mathrm{O}_{2}$ & $2 \% \mathrm{O}_{2}$ & $20 \% \mathrm{O}_{2}$ & $2 \% \mathrm{O}_{2}$ \\
\hline \multicolumn{5}{|c|}{ Free fatty acid } \\
\hline LPDS & $27.7 \pm 1.3$ & & $30.5 \pm 1.8$ & \\
\hline NRS & $23.8 \pm 0.8$ & $34.3 \pm 1.8^{* * *}$ & $27.4 \pm 0.7$ & $39.4 \pm 1.2^{* * *}$ \\
\hline HRS & $25.8 \pm 1.1$ & $32.6 \pm 2.1^{* *}$ & $27.4 \pm 2.3$ & $32.9 \pm 1.2^{*}$ \\
\hline \multicolumn{5}{|c|}{ Triglyceride } \\
\hline LPDS & $9.4 \pm 1.7$ & & $9.1 \pm 0.8$ & \\
\hline NRS & $5.4 \pm 0.5$ & $127.3 \pm 1.5^{* * *}$ & $6.6 \pm 0.2$ & $113.0 \pm 5.3^{* * *}$ \\
\hline HRS & $67.6 \pm 2.1$ & $292.3 \pm 9.7 * * *$ & $86.0 \pm 1.0$ & $250.3 \pm 5.7^{* * *}$ \\
\hline \multicolumn{5}{|c|}{ Free cholesterol } \\
\hline LPDS & $12.8 \pm 0.7$ & & $14.4 \pm 0.4$ & \\
\hline NRS & $10.7 \pm 0.1$ & $11.2 \pm 0.4$ & $11.5 \pm 0.4$ & $9.5 \pm 0.3^{* * *}$ \\
\hline HRS & $14.6 \pm 0.2$ & $21.3 \pm 1.1^{* * *}$ & $15.4 \pm 1.0$ & $19.8 \pm 1.5^{*}$ \\
\hline \multicolumn{5}{|c|}{ Esterified cholesterol } \\
\hline LPDS & $1.7 \pm 0.6$ & & $1.1 \pm 0.3$ & \\
\hline NRS & $0.6 \pm 0.2$ & $0.7 \pm 0.7$ & $0.4 \pm 0.4$ & $0.9 \pm 0.2$ \\
\hline HRS & $14.4 \pm 0.8$ & $32.5 \pm 2.3^{* * *}$ & $12.4 \pm 1.3$ & 23. $2 \pm 1.0^{* * *}$ \\
\hline \multicolumn{5}{|c|}{ Phospholipid } \\
\hline LPDS & $161 \pm 3$ & & $149 \pm 2$ & \\
\hline NRS & $168 \pm 4$ & $166 \pm 2$ & $168 \pm 4$ & $166 \pm 3$ \\
\hline HRS & $183 \pm 5$ & $184 \pm 7$ & $176 \pm 3$ & $175 \pm 2$ \\
\hline
\end{tabular}

Cells were grown to subconfluence in culture medium containing $10 \%$ newborn calf serum, rinsed once with PBS, and incubated in medium containing LPDS $(2.5 \mathrm{mg}$ protein $/ \mathrm{ml})$ for $24 \mathrm{~h}$. Then the medium was removed and medium containing $20 \%$ NRS or $20 \% \mathrm{HRS}$ was added to each dish. The dishes were transferred either to the control $\left(20 \% \mathrm{O}_{2}, 75 \% \mathrm{~N}_{2}\right.$, and $\left.5 \% \mathrm{CO}_{2}\right)$ or the hypoxic $\left(2 \% \mathrm{O}_{2}, 93 \% \mathrm{~N}_{2}\right.$, and $\left.5 \% \mathrm{CO}_{2}\right)$ incubator, in which the cells were incubated for $48 \mathrm{~h}$. The total cholesterol, triglyceride, and phospholipid values of HRS were $2,200 \mathrm{mg} / \mathrm{dl}, 210 \mathrm{mg} / \mathrm{dl}$, and $592 \mathrm{mg} / \mathrm{dl}$, respectively, and those of NRS were $43 \mathrm{mg} / \mathrm{dl}, 22$ $\mathrm{mg} / \mathrm{dl}$, and $57 \mathrm{mg} / \mathrm{dl}$, respectively. All results are expressed in $\mu \mathrm{g} / \mathrm{mg}$ of cell protein. Each value represents the mean $\pm \mathrm{SD}$ of triplicate cultures. ${ }^{*} p<0.05 ; * * p<0.01 ; * * * p<0.001$ as compared with control cells.

levels of control cells incubated in the medium containing $20 \%$ HRS were markedly higher than those of cells incubated in the medium containing $20 \%$ NRS. Moreover, there was a much higher TG accumulation in the hypoxic cells. HRS induced cholesterol accumulation, especially that of the esterified form, not only in normal cells but also in WHHL cells. The free cholesterol levels of hypoxic cells incubated with the medium containing $20 \%$ HRS were higher than those of control cells by $46 \%$ in normal cells and $29 \%$ in WHHL cells. Moreover, the esterified cholesterol levels of hypoxic cells incubated with $20 \%$ HRS were much higher than those of control cells by 2.3-fold in normal cells and 1.9-fold in WHHL cells. On the other hand, in the medium containing $20 \%$ NRS, hypoxia did not promote the accumulation of either free or esterified cholesterol in the cells. The PL levels of cells incubated with $20 \%$ HRS were a little higher than those of the 


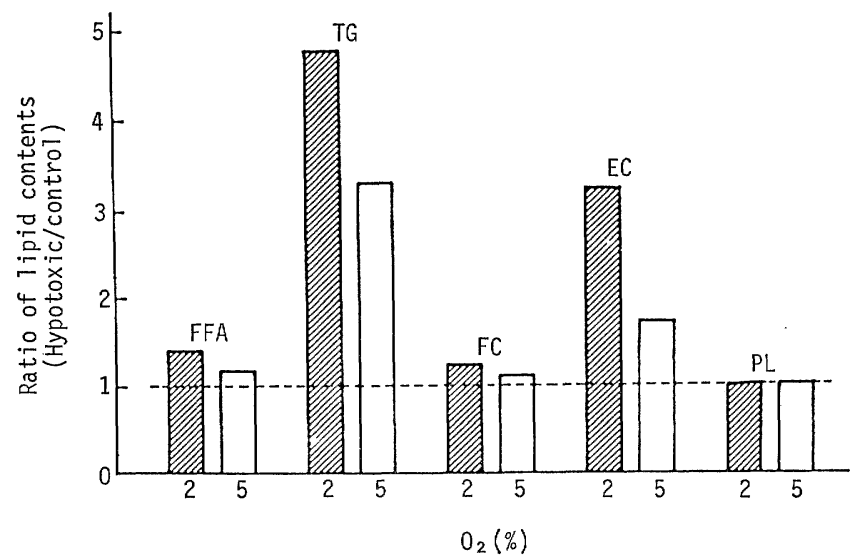

Fig. 1. The ratio of lipid content in hypoxic cells $\left(2 \%\right.$ or $\left.5 \% \mathrm{O}_{2}\right)$ to control cells $\left(20 \% \mathrm{O}_{2}\right)$ incubated in medium containing $20 \%$ HRS for $48 \mathrm{~h}$. Normal fibroblasts were grown to subconfluence in culture medium containing $10 \%$ newborn calf serum, rinsed once with PBS, and incubated in medium containing LPDS $(2.5 \mathrm{mg}$ protein $/ \mathrm{ml})$ for $24 \mathrm{~h}$. Then the latter medium was removed and that containing $20 \%$ HRS was added to each dish. The dishes were transferred either to the control $\left(20 \% \mathrm{O}_{2}\right)$ or the hypoxic $\left(2 \% \mathrm{O}_{2}\right.$ or $\left.5 \% \mathrm{O}_{2}\right)$ incubator and the cells were incubated for $48 \mathrm{~h}$. The total cholesterol, triglyceride and phospholipid values of HRS were $1,765,193$, and $451 \mathrm{mg} / \mathrm{dl}$, respectively. The $2 \% \mathrm{O}_{2}$ and $5 \% \mathrm{O}_{2}$ series were carried out separately. The ratios were obtained from each experiment. Each bar represents the value of the mean of triplicate cultures under hypoxic conditions $\left(2 \% \mathrm{O}_{2}\right.$ or $\left.5 \% \mathrm{O}_{2}\right) /$ control conditions $\left(20 \% \mathrm{O}_{2}\right)$, respectively. FFA, Free fatty acid; TG, triglyceride; FC, free cholesterol; EC, esterified cholesterol; PL, phospholipid.

cells incubated with $20 \%$ NRS, but there was no significant difference between control and hypoxic cells. Thus, after a $48 \mathrm{~h}$ incubation of normal fibroblasts in the medium with $20 \%$ NRS, the FFA level increased slightly and TG level increased markedly in hypoxic cells. On the other hand, in the medium with $20 \%$ HRS, the free cholesterol level increased slightly and the esterified cholesterol level increased markedly in addition to the increased FFA and TG levels in the hypoxic cells. These lipid increases in normal fibroblasts were almost identical with those in the WHHL fibroblasts.

Another experiment was carried out using normal fibroblasts. Figure 1 shows the ratio of lipid content in hypoxic cells $\left(2 \% \mathrm{O}_{2}\right.$ or $\left.5 \% \mathrm{O}_{2}\right)$ to control cells $(20 \%$ $\mathrm{O}_{2}$ ) incubated in the medium containing $20 \%$ HRS for $48 \mathrm{~h}$. The ratios of FFA and free cholesterol increased slightly and those of TG and esterified cholesterol increased markedly, while the ratio of PL did not increased. These increases correlated inversely with $\mathrm{O}_{2}$ concentrations.

\section{DISCUSSION}

We previously reported that hypoxia $\left(2 \% \mathrm{O}_{2}\right)$ promoted cholesterol accumulation, especially that of the esterified form, in cultured rabbit aortic smooth muscle 
cells in the presence of hyperlipemic serum [2]. In the present study, not only cholesterol but also other lipids (FFA, TG, and PL) were measured in normal fibroblasts and WHHL fibroblasts incubated under hypoxic conditions for $48 \mathrm{~h}$. Pietila et al. reported that the cellular content of cholesterol in smooth muscle cells cultured from rabbit aorta in medium containing $10 \%$ fetal calf serum showed no difference between control cells and those kept under hypoxic conditions [12]. Moreover, Gordon reported that hypoxic cultured mouse fibroblasts grown in a suspension culture system with $10 \%$ horse serum showed no significant changes in cellular cholesterol or phospholipid content, although increased FFA and TG levels were noted [13]. In the present study, after a $48 \mathrm{~h}$ incubation in medium with $20 \%$ NRS, the FFA level was increased slightly, and the TG level, markedly, in hypoxic cells. On the other hand, in medium with $20 \%$ HRS, in addition to the increased FFA and TG levels, a marked accumulation of esterified cholesterol and a lesser extent of free cholesterol accumulation were noted in hypoxic cells (Table 1 and Fig. 1).

Filipovic et al. reported that hypoxia, inducing a rise of NADH/NAD ratio, increased FFA synthesis in arterial tissue [14, 15]. Spector et al. reported that FFA oxidation took place mainly in the mitochondria and required energy from oxidative phosphorylation [16]. The increased fatty acid synthesis and the impairment of utilization of FFA in hypoxia will result in increased esterification, since the intracellular level of FFA is closely regulated [17]. Excessive FFA, which is stored as TG under normolipemic conditions, seems to be stored not only as TG but also as cholesterol esters under hyperlipemic conditions (Table 1 and Fig. 1). It is thought that both excessive FFA and excessive cholesterol are key factors in cholesterol ester accumulation in hypoxic cells.

Cultured skin fibroblasts possess specific high affinity receptors that bind LDL on their cell surface. It is believed that the receptor-mediated uptake of LDL particles is the major process by which most extrahepatic cells take up cholesterol [1]. Hyperlipemic serum from cholesterol-fed animals induces accumulation of esterified cholesterol in tissue culture cells [18--20]. And in our study, when cultured rabbit fibroblasts were incubated with $20 \%$ HRS for $48 \mathrm{~h}$, lipids including free and esterified cholesterol accumulated in WHHL fibroblasts almost as much as in normal fibroblasts. This indicates that LDL receptor-independent uptake of lipoproteins plays a major role in cellular lipid accumulation under hyperlipemic conditions. Hypoxic effects on lipid accumulation in cultured cells were not mediated by LDL receptors, since there were no marked differences in cellular lipid accumulation under hypoxic conditions between normal fibroblasts and WHHL fibroblasts.

In hypoxic cells under hyperlipemic conditions, the ratio of PL to cholesterol content ratio fell, since the PL content did not increase although the cholesterol content did. Adams reported that the PL-cholesterol ratio fell in the later stage of atheroma and synthesis of PL was an early defense mechanism of the arterial wall against the infiltration of cholesterol [21]. Kjeldsen et al. showed that systemic 
hypoxia promoted aortic atherosclerosis with increases in plasma cholesterol and TG levels in cholesterol-fed rabbits and also that the aortic content of total cholesterol and TG were higher in the rabbit under hypoxia, while no changes were seen in aortic PL [22]. The profile of lipid accumulation in hypoxic cells with HRS in our study is similar to that in aortic atheroma under hypoxic conditions in Kjeldsen's report. We previously reported that in the WHHL rabbit systemic hypoxia aggravated aortic atherosclerosis without causing a further increase in the plasma cholesterol level [23]. Our previous in vivo study and the present in vitro study suggested that enhanced lipid accumulation in the arterial wall by systemic hypoxia is produced not through the increased plasma lipid levels but through the direct effect of hypoxia on the tissue.

The present study indicates that under hyperlipemic conditions, non-LDL receptor mediated uptake of lipoproteins plays an important role in cellular lipid deposition and that tissue hypoxia promotes the lipid accumulation in peripheral cells by a LDL receptor-independent mechanism.

\section{REFERENCES}

1. Goldstein, J.L., and Brown, M.S. (1974): Binding and degradation of low density lipoproteins by cultured human fibroblasts. J. Biol. Chem., 249, 5153-5162.

2. Tsukitani, M., Okamoto, R., and Fukuzaki, H. (1984): Effect of hypoxia on cholesterol accumulation in cultured rabbit aortic smooth muscle cells. Atherosclerosis, 52, 167-174.

3. Goldstein, J.L., and Brown, M.S. (1977): The low density lipoprotein pathway and its relation to atherosclerosis. Ann. Rev. Biochem., 46, 897-930.

4. Tanzawa, K., Shimada, Y., Kuroda, M., Tsujita, Y., Arai, M., and Watanabe, Y. (1980): WHHL rabbit: a low density lipoprotein receptor-deficient animal model for familial hypercholesterolemia. FEBS Lett., 118, 81-84.

5. Kita, T., Brown, M.S., Watanabe, Y., and Goldstein, J.L. (1981): Deficiency of low density lipoprotein receptors in liver and adrenal gland of the WHHL rabbit, an animal model of familial hypercholesterolemia. Proc. Natl. Acad. Sci. USA, 78, 2268-2272.

6. Tsukitani, M., Okamoto, R., Suehiro, A., Hatani, M., Fujino, M., Imai, N., Takano, S., Watanabe, Y., and Fukuzaki, H. (1982): LDL receptor activity of cultured arterial smooth muscle cells from genetically hyperlipidemic rabbits (WHHL rabbit). Kobe J. Med. Sci., 28, 171-179

7. Havel, R.J., Edler, H.A., and Bragdon, J.H. (1955): The distribution and chemical composition of ultracentrifugally separated lipoproteins in human serum. J. Clin. Invest., 34, 13451353.

8. Folch, J., Lees, M., and Sloan Stanley, G.H. (1957): A simple method for the isolation and purification of total lipids from animal tissues. J. Biol. Chem., 226, 497-509.

9. Lowry, O.H., Rosebrough, H.J., Farr, A.L., and Randall, R.J. (1951): Protein measurement with the Folin phenol reagent. J. Biol. Chem., 193, 265-275.

10. Heider, J.G., and Boyett, R.L. (1978): The picomole determination of free and total cholesterol in cells in culture. J. Lipid Res., 19, 514-518.

11. Hoeflmayr, V.J., and Fried, R. (1966): Eine methode zur routinema $\beta$ igen bestimmung des lipidphosphors und der phosphatide. Med. Ernahr., 7, 9-10.

12. Pietila, K., and Jaakkola, O. (1984): Effect of hypoxia on the synthesis of glycosaminoglycans and collagen by rabbit aortic smooth muscle cells in culture. Atherosclerosis, 50, 183-190.

Vol. 2, No. 3, 1987 
13. Gordon, G.B., Barcza, M.A., and Bush, M.E. (1977): Lipid accumulation in hypoxic tissue culture cells. Am. J. Pathol., 88, 663-678.

14. Filipovic, I., and Buddecke, E. (1971): Increased fatty acid synthesis in arterial tissue hypoxia. Eur. J. Biochem., 20, 587-592.

15. Filipovic, I., and Rutemoller, M. (1976): Comparative studies on fatty acid synthesis in atherosclerotic and hypoxic human aorta. Atherosclerosis, 24, 457-469.

16 Spector, A. (1971): Metabolism of free fatty acids, in Biochemistry and Pharmacology of Free Fatty Acids. Progress in Biochemical Pharmacology Series, Vol. 6., ed. by Holms, W.L., and Bortz, W.M., S. Karger AG, Basel, pp. 130-176.

17. Spector, A. (1972): Fatty acid, glyceride and phospholipid metabolism, in Growth, Nutrition and Metabolism of Cells in Culture, Vol. 1., ed. by Rothblat, G.H., and Christofalo, V.J., Academic Press, Inc., New York, pp. 257-296.

18. Bates, S.R., and Wissler, R.W. (1976): Effect of hyperlipemic serum on cholesterol accumulation in monkey aortic medial cells. Biochim. Biophys. Acta, 450, 78-88.

19. Pearson, J.D. (1976): Lipid metabolism in cultured smooth muscle cells and comparison with other types. Part 1. Composition of cells grown in hyperlipemic serum. Atherosclerosis, 24, 233-242.

20. Chen, R.M., and Dzoga, K. (1977): Effect of hyperlipemic serum lipoproteins on the lipid accumulation and cholesterol flux of rabbit aortic medial cells. Atherosclerosis, 28, 339-353.

21. Adams, C.W.M. (1964): Arteriosclerosis in man, other mammals and birds. Biol. Rev., 39, 372-423.

22. Kjeldsen, K., Wanstrup, J., and Astrup, P. (1968): Enhancing influence of arterial hypoxia on the development of atheromatosis in cholesterol-fed rabbits. J. Atheroscler. Res., 8, 835845.

23. Okamoto, R., Hatani, M., Tsukitani, M., Suehiro, A., Fujino, M., Imai, N., Takano, S., Watanabe, Y., and Fukuzaki, H. (1983): The effect of oxygen on the development of atherosclerosis in WHHL rabbits. Atherosclerosis, 47, 47-53. 